\title{
Do Norms on Contribution Behavior Affect Intrinsic Motivation? Field-Experimental Evidence from Germany
}

\author{
Pierre C. Boyer \\ Nadja Dwenger \\ Johannes Rincke
}

CESIFO WORKING PAPER NO. 5998

CATEGORY 1: PuBliC FINANCE

JULY 2016

An electronic version of the paper may be downloaded

- from the SSRN website:

- from the RePEc website:

- from the CESifo website:

WwW.SSRN.com

www.RePEc.org

www.CESifo-group.org/wp

ISSN 2364-1428 


\title{
Do Norms on Contribution Behavior Affect Intrinsic Motivation? Field-Experimental Evidence from Germany
}

\begin{abstract}
This paper studies how imposing norms on contribution behavior affects individuals' intrinsic motivation. We consider the church levy, which the Catholic Church in Germany collects as a charitable donation, despite the fact that the levy is legally a tax. We design a randomized field experiment with treatments informing individuals that the levy is a tax. We demonstrate that treatment effects differ across motivational types. Among weakly intrinsically motivated individuals, communicating the legal norm results in a significant crowd-out of intrinsic motivation. In contrast, strongly intrinsically motivated individuals do not show any treatment response.
\end{abstract}

JEL-Codes: C930, D030, H260, H410.

Keywords: intrinsic motivation, crowding out, charitable giving, norms, taxes, public goods, randomized field experiment.

\author{
Pierre C. Boyer \\ École Polytechnique-CREST \\ France - 91128 Palaiseau \\ pierre.boyer@polytechnique.edu
}

Nadja Dwenger

University of Hohenheim

Germany - 70593 Stuttgart

nadja.dwenger@uni-hohenheim.de
Johannes Rincke

University of Erlangen-Nuremberg

Germany - 90403 Nuremberg

johannes.rincke@fau.de

July 6, 2016

We are grateful for financial support from the Schoeller Foundation, the Emerging Field Initiative of the University of Erlangen-Nuremberg, and the Investissements d'Avenir (ANR-11IDEX-0003/Labex Ecodec/ANR-11-LABX-0047). 


\section{Introduction}

How do external incentives affect behavior? For a long time economists have focused on how external incentives shape individuals' extrinsic motivation. More recently, they have recognized that individual behavior is also driven by intrinsic motivation and have started to integrate into their models the view that external incentives can actually backfire by crowding out this motivation (Bénabou and Tirole, 2003, 2006; Sliwka, 2007). ${ }^{1}$ This paper adds to an emerging literature that tries to identify this crowd-out empirically and asks whether it is economically relevant. We focus on an outcome that is of general importance: the willingness of individuals to contribute to public goods provision. Specifically, we focus on the role of taxes as externally imposed norms on contribution behavior, as opposed to voluntary contributions. We discuss the motivational effect of externally imposed norms in a setting where we are able to obtain a good proxy for individuals' initial strength of intrinsic motivation. This allows us to study heterogenous responses across different motivational types when voluntary contributions are transformed into compulsory tax payments (and vice versa).

We implement our research design in the context of the local church levy in Germany. We focus on an urban area in Bavaria, where the Catholic Church has collected the local church levy as a charitable donation for decades, despite the fact that the levy is legally a tax on all church members. Starting from a pure voluntary-giving baseline without any external incentives, we conduct a randomized field experiment with letter treatments informing individuals that the church levy is in fact a tax. Thereby, we can study how payment behavior changes if public goods are financed through compulsory tax payments instead of voluntary contributions. While this one-of-a-kind feature of the local church levy allows for novel insights on the crowd-out of intrinsic motivation, there is of course a potential trade-off with external validity, which we discuss in the paper.

In our field experiment we randomly assign a total of almost 40,000 individuals to a control group and three different treatment groups: a compulsory tax, a voluntary tax, and a donation letter group. The compulsory tax letter highlights the fact that the church levy is a legally binding tax. The letter encourages overpayments and explains that payments which exceed the tax owed are treated as charitable donations. The voluntary tax letter communicates that the church levy is legally a tax, but informs recipients that the church administration considers the levy a charitable contribution on a purely voluntary basis. Both tax letters are naturally compared to the donation letter group. The donation letter states that the church considers the levy a purely voluntary

\footnotetext{
${ }^{1}$ In psychology and sociology, the extrinsic-intrinsic crowd-out has been discussed somewhat earlier (Deci, 1971, 1975).
} 
contribution. As the tax letters mention the amount most individuals owe according to the tax law, the donation letter refers to the same amount as a suggested donation. To measure the effect of mentioning the amount and thus providing a reference point, we compare the donation letter group to the control group, which receives the same letter as in previous years (voluntary contribution, no suggested amount).

It is a major advantage of our setting that we can derive a good proxy for the strength of intrinsic motivation in the baseline. ${ }^{2}$ To do so we exploit the fact that there were no external incentives in place initially such that any contributions made prior to treatment necessarily reflect individuals' intrinsic motivation. We use administrative data on individual contributions in the eight years prior to treatment to determine the relative frequency of pre-treatment contributions as a straightforward measure of individuals' baseline motivation. We distinguish between two main motivational types: The group of baseline non-contributors consists of individuals who never contributed in the baseline. Individuals of this type reveal that their intrinsic motivation is too low to trigger any financial contribution. A second group consists of individuals who have contributed at least once, thereby revealing some baseline intrinsic motivation. We call these individuals the intrinsically motivated and use the baseline probability of contributing as a continuous measure of their intrinsic motivation.

The findings from the field experiment reveal a distinct heterogeneity in treatment responses. First, individuals with regular baseline contributions (the strongly intrinsically motivated) do not show any response to the information that the church levy is a tax. This finding stands in stark contrast to the behavior of individuals who contributed only occasionally in the baseline (the weakly intrinsically motivated): individuals in this group significantly reduce their payments in response to the voluntary tax letter, but do not show any net response to the compulsory tax treatment. This behavior is consistent with the notion that imposing norms on contribution behavior crowds out intrinsic motivation, but that a sufficiently binding tax norm compensates the crowd-out. The crowd-out identified by our field experiment is economically significant: in the voluntary tax treatment, subjects from the bottom of the distribution of baseline motivation are about $19 \%$ less likely to make a positive contribution compared to the donation letter treatment. Finally, baseline non-contributors significantly increase their payments if they receive the compulsory tax letter but do not respond to the voluntary tax letter that communicates the existence of a non-binding legal norm.

\footnotetext{
${ }^{2}$ The only field-experimental studies we are aware of that look at differences between motivational types when studying the extrinsic-intrinsic crowd-out are Ashraf et al. (2014) and Huffman and Bognanno (2014). Ashraf et al. (2014) derive their measures of agents' motivation from behavior in a dictator game and from survey responses. Huffman and Bognanno (2014) analyze heterogeneous responses to incentives in a real work setting and distinguish between motivational types by means of a post-treatment survey.
} 
Our findings prove to be valid across a number of robustness checks. Most importantly, our main findings are robust to using different measures of intrinsic motivation, ranging from average amount of payment in the baseline to measures derived from an extensive post-treatment survey. Interestingly, the heterogeneity in treatment responses results in a situation where the average treatment effects are small and insignificant, despite the fact that several subgroups of individuals show strong behavioral responses. One of our main conclusions is that in order to predict how individuals respond to external incentives, it is essential to account for the heterogeneity in motivational types.

To interpret our findings, we offer a simple conceptual framework of contribution behavior under different collection regimes, ranging from voluntary contributions to a tax that might be implemented as a more or less binding norm. The model helps to understand the heterogeneity in treatment responses by disentangling how the mode of collection affects the profile of contributions across different motivational types.

Our contribution relates to various strands of literature. First, we present new evidence on the extrinsic-intrinsic crowd-out, relating our work to Frey and Oberholzer-Gee (1997), Gneezy and Rusticcini (2000a,b), Falk and Kosfeld (2006) and Mellström and Johannesson (2008) (who find evidence for crowding out) and Lacetera et al. (2012), Ashraf et al. (2014) and Chetty et al. (2014) (who conclude that it is of minor importance). ${ }^{3}$ In contrast to most previous work on the extrinsicintrinsic crowd-out, we study a context where social image concerns are of little or no importance: individual church levy contributions are strictly private, and the church administration collecting the payments does not inform local parishes about individual contributions. This differentiates our work conceptually from contexts where external incentives dilute the signaling value of prosocial behavior and thereby reduce individuals' social image motivation for prosocial activities (Ariely et al., 2009; Friedrichsen and Engelmann, 2014). ${ }^{4}$

Second, by experimentally shifting the framing from donation to tax, we bridge the gap between the charitable giving and the tax compliance literature. While it is well established that intrinsic motivation in the form of 'warm glow' is important for charitable giving (Andreoni, 1989, 1990), the role of intrinsic motivation in the context of tax compliance is less clear (Andreoni et al., 1998; Kleven et al., 2011; Luttmer and Singhal, 2014). While some studies have shown that tax morale and internalized social norms can be relevant (Del Carpio, 2013; Pruckner and Sausgruber, 2013; Fellner et al., 2013; Hallsworth et al., 2014), most of the field-experimental literature on tax compliance pioneered by Slemrod et al. (2001) and Blumenthal et al. (2001) focuses on external

\footnotetext{
${ }^{3}$ The crowd-out studied in this literature is conceptually different from the one discussed by Andreoni (1993), who explores if government contributions towards privately provided public goods crowd out private contributions.

${ }^{4}$ Our design also avoids confounding factors like retaliation or loss of morale (Esteves-Sorensen et al., 2013).
} 
incentives. Dwenger et al. (2016) contrast policies aiming at a stronger enforcement of taxes with reward-based approaches in a field experiment. They conclude that intrinsic motivation is important to understand tax compliance behavior, but that the positive effects of tax enforcement overcompensate any associated loss in intrinsic motivation. Taken together, our results and the findings of the tax compliance literature suggest that imposing a tax norm as such crowds out intrinsic motivation, but the adverse effects of increasing the level of enforcement given a tax frame appear to be modest. From a methodological point of view, we add to an expanding literature using field experiments to study charitable giving (Falk, 2007; Landry et al., 2010; Huck and Rasul, 2011; DellaVigna et al., 2012).

The remainder of the paper is organized as follows. Section 2 presents the institutional background. The design of the field experiment and the data are discussed in Section 3. Our main results are presented in Section 4. Section 5 discusses the robustness of our findings and underlying mechanisms and Section 6 concludes.

\section{Institutional Background: The Local Church Levy}

This study focuses on the local church levy (Kirchgeld) in Germany. The church levy is the local component of overall church finances in Germany and is raised in addition to the general church tax, which is collected by state tax authorities on behalf of the churches. The levy is collected by local parishes. In conjunction with the Catholic Church, we implement our field experiment in an urban area in Bavaria where the church levy is raised jointly by 29 parishes forming a church district.

It is of key importance for our study that the church district has always handled the local church levy as a charitable donation on a purely voluntary basis. ${ }^{5}$ To ask for the church levy donation, the district administration sends out a yearly solicitation letter to all full-age members. ${ }^{6}$ The letter asks for a donation and informs church members that the funds are used to co-finance reconstruction works on churches, clergy houses, and parish centers. The purpose of the solicitation letter is communicated in the first paragraph: "As every year, we kindly ask you herewith for your local church levy contribution. [...] The church district considers the church levy a contribution equivalent to a charitable donation." 7 Attached to the letter is a bank transfer form. Given the

\footnotetext{
${ }^{5}$ Dwenger et al. (2016) study the local church tax collected by the Protestant Church in a different metropolitan area. In contrast to our setting, the Protestant Church has always highlighted the fact that the local church tax is a compulsory payment.

${ }^{6}$ Married couples in which both spouses are church members receive only one letter. We therefore stratify our samples according to household type (see Section 3.2).

${ }^{7}$ Pre-treatment, the solicitation letter was very similar across years. The version cited here was used in the last pre-treatment year 2012.
} 
framing as a voluntary contribution, few people pay the levy: in the baseline, about $9 \%$ of church members initiate a bank transfer after receiving the letter.

The practice of collecting the church levy as a charitable donation stands in sharp contrast to the underlying legal framework which states that the church levy is a tax. According to the statutes of the church district under consideration, the church levy is a compulsory payment depending on church members' gross income. The amount due ranges from $€ 2.5$ to $€ 15$ for individuals exceeding the exemption level of $€ 1,800$ annual income. ${ }^{8}$ Table A1 in the Online Appendix demonstrates that in practice, the vast majority of individuals subject to the church levy owes the maximum amount of $€ 15$ (77\% of single and $66 \%$ of married taxpayers). In our experiment, we exploit the specifics of the church levy and truthfully shift the collection mode from voluntary contribution to compulsory tax - a variation that would be very difficult to implement in most other settings.

Why is the levy collected on a voluntary basis? The local church administration has no information on church members' incomes and thus cannot enforce the levy as an income-dependent tax. ${ }^{9}$ Left with the options to ask for a voluntary contribution or to frame the levy as an (unenforced) tax, the church administration has decided early on to rely on voluntary contributions. ${ }^{10}$ By doing so, the district administration manages to collect average payments (conditional on paying) which exceed the maximum tax amount of $€ 15$ (€33.82 in 2012). In fact, the decision not to collect the church levy as a tax may reflect a perception among church officials about a tradeoff between individuals' intrinsic and extrinsic motivation.

To gain a better understanding of the church tax system in Germany, we briefly comment on a few more institutional details. First, both charitable donations and church levy payments are deductible when filing for the personal income tax. Hence, the costs associated with paying the levy are independent of whether the church collects the levy as a tax or as a voluntary contribution. Second, contributing nothing or underpaying relative to the amount legally owed has no consequences whatsoever. Third, information on individual contributions remains strictly private. While the personal interaction between church members and the clergy or other church staff takes place at the level of the local parishes, the church district administration typically does not interact with individual church members. The church district collects the church levy and distributes the revenues to local parishes, but it does not provide information on individual church levy contributions to local parishes. This implies that social image concerns related to prosocial behavior (Bénabou and Tirole, 2006; Ariely et al., 2009) are not pertinent in our setting. Fourth,

\footnotetext{
${ }^{8}$ The schedule follows a step function with discrete jumps of $€ 2.50$ at incomes of $€ 5,000, € 7,500, \ldots, € 12,500$.

${ }^{9}$ Even if income information was available, enforcement would hardly be cost-efficient given the modest size of tax liabilities.

${ }^{10}$ The earliest version of the local solicitation letter we could access is from 1971. It states explicitly that the levy is collected on a voluntary basis.
} 
treatment take-up in our setting is very high. In the year after our intervention, Cagala et al. (2015) conducted a randomized phone survey on take-up among recipients of the solicitation letter $(N=101) .96 \%$ of respondents acknowledged that they received the solicitation letter, and $83 \%$ stated that they opened the letter.

The setting we consider is specific, which limits the external validity of our study. First, if some church members prefer to donate outside the context of the local church levy this leads us to underestimate their baseline intrinsic motivation. This should leave our findings unaffected (and only raise standard errors) as potential misclassifications are uncorrelated with (randomized) treatment. Also, direct donations account for less than $3 \%$ of total church revenues. This should limit misclassifications to a minimum. Survey responses (see part 5.3) show that weakly intrinsically motivated individuals, for which the crowd-out is strongest, are the least likely to attend church services. This should further alleviate concerns about individuals considering the local church levy and direct donations to be substitutes. Second, if mainly pro-social individuals become church members this would lead us to overstate baseline intrinsic motivation. Our general findings, however, should still hold as treatment is again uncorrelated with potential mismeasurement of intrinsic motivation. ${ }^{11}$ Third, if church members value church services more than the public services financed by other taxes, this could raise baseline intrinsic motivation compared to other contexts. This is very unlikely, though, as most church members make use of church services rather infrequently. ${ }^{12}$

\section{$3 \quad$ Experimental Design and Data}

\subsection{Randomized Natural Field Experiment}

We exploit the church levy setting to design a field experiment which shifts the mode of financing of a public good from purely voluntary contributions to compulsory tax payments. In conjunction with the Catholic Church we manipulated the content of the cover letter of the mail-out in 2013 and varied the framing for contributions to the church levy funds. Recipients were randomly assigned into a control group and three treatment groups: a donation treatment, a voluntary tax treatment, and a compulsory tax treatment. ${ }^{13}$

\footnotetext{
${ }^{11}$ Notwithstanding the above, our sample should rather accurately reflect the strength of intrinsic motivation in the overall population: individuals become church members by default when baptized (typically at birth), and church members are very similar to the overall population in terms of giving behavior (see Table A1 in the Online Appendix).

${ }^{12}$ In the area studied, less than $12 \%$ of church members attend a religious service on Sundays (Catholic Church 2014).

${ }^{13}$ 'Voluntary tax' is an established term in the public finance literature. Cooper (1979) and Slemrod (1998) use and discuss the term, pointing to the fact that when designing tax systems, governments strongly rely on 'voluntary
} 
Control letter. The content of the control letter corresponds to the letter sent out in earlier years. The exact wording and format of the control letter is shown in the Online Appendix. The letter emphasizes that the church levy is considered a charitable donation and highlights the good cause. It specifies neither the amount church members might contribute nor a payment deadline. The second page of the letter informs recipients about institutional details of the church levy. The letter provides no external incentive for contributing to the public good.

Donation letter. Apart from shortening the first paragraph, the main difference to the control group letter is that the donation letter mentions the amount of $€ 15$ (the amount that most individuals legally owe). The first paragraph of the letter reads as follows:

"As every year, we kindly ask you herewith for your local church levy contribution (see overleaf for legal background). The church levy is staggered according to income and equal to $€ 15$ for the highest income bracket. The church district considers the church levy a contribution equivalent to a charitable donation. You decide how much you wish to contribute."

To determine the effect of providing a reference point of $€ 15$, we compare the donation letter to the control letter. All else equal, we might expect that the treatment increases the probability of contributing among baseline non-contributors: some non-contributors might be uncertain about how much to give in the baseline and potentially start contributing once they receive guidance on that issue. If the reference amount mentioned in the letter serves as an anchor we should additionally see a treatment response of baseline contributors at the intensive margin: we expect individuals with baseline contributions above $€ 15$ to reduce and individuals with baseline contributions below $€ 15$ to increase their contribution.

The two subsequent treatment letters communicate the existence of a legal norm by varying the first paragraph of the donation letter.

Compulsory tax letter. The compulsory tax letter communicates a binding legal norm to contribute to the public good by informing individuals that the church levy forms part of the church tax. The first paragraph of the compulsory tax letter reads as follows:

"As every year, we kindly ask you herewith for your local church levy contribution (see overleaf for legal background). The church levy is part of the church tax and is therefore a compulsory payment. The levy is staggered according to income and equal to $€ 15$ for the highest income bracket. The church district considers any church levy payment that exceeds the compulsory amount a contribution equivalent to a charitable donation. You decide how much you wish to contribute."

Voluntary tax letter. The voluntary tax letter communicates the existence of the legal norm, but frames the norm as non-binding. This is communicated as follows:

compliance'. 
"As every year, we kindly ask you herewith for your local church levy contribution (see overleaf for legal background). The church levy is part of the church tax and is therefore a compulsory payment. The levy is staggered according to income and equal to $€ 15$ for the highest income bracket. We abstain, however, from collecting the church levy as a compulsory payment. Instead, the church district considers the church levy a contribution equivalent to a charitable donation. You decide how much you wish to contribute."

The natural comparison group for both tax treatments is the donation letter. All else equal, baseline contributors should reduce their contributions if their intrinsic motivation is crowded out by the tax framing. We expect the drop in contributions to be most pronounced among recipients of the voluntary tax letter as the crowd-out among recipients of the compulsory tax letter might be (partly) compensated by an incentive to comply with a binding norm. For baseline noncontributors, making the legal norm binding is expected to increase compliance at no cost. For this group, we thus expect the compulsory tax letter to dominate (in terms of contributions) any other letter.

\subsection{Data and Measure of Intrinsic Motivation}

Data. We use administrative records of church levy payments made in years 2005-2013. In our empirical analysis we include all payments received within the first 20 weeks of the experiment (corresponding to $94 \%$ of all payments effected until December 31, 2013). The data records the amount and date of each payment together with individual characteristics such as marital status, sex, and age. Our sample consists of 39,788 individuals. ${ }^{14}$ In 2012, the year before the experiment, $11.5 \%$ of individuals in the sample made a contribution to the church levy funds. Figure 1 shows the distribution of strictly positive contributions in 2012 .

Table A1 in the Online Appendix provides evidence on the representativeness of our sample by comparing average characteristics of individuals in our sample to those of the full population living in the urban area we study, based on personal income tax records. The table shows that Catholic Church members are very similar to the overall population in terms of age, distribution of income, and charitable giving behavior.

Our sampling procedure uses strata defined by past contribution behavior, household type and age. Table 1 reports randomization checks. The average probability of contributing in baseline year

\footnotetext{
${ }^{14}$ In total, the church district mailed the solicitation letter to 63,177 individuals. To prevent spillovers (Rincke and Traxler, 2011), we excluded church employees interacting with members and individuals who share the same name and address with at least two other individuals. This left us with 56,750 individuals for treatment, of which 16,962 individuals were assigned to treatments belonging to a separate research agenda on gift exchange (Cagala et al., 2015). We assigned to the gift exchange treatments only individuals who did not make any positive contribution in the two years prior to treatment.
} 
2012 is $11 \%$, with an (unconditional) average contribution of $€ 3.88$. F-tests of joint significance of covariates reveal no differences in observable characteristics across treatment groups. Additional descriptives are provided in the Online Appendix, Table A2, where we repeat the randomization checks for the subsample of baseline contributors (at least one positive contribution in years 2005 to 2012 , comprising $17.1 \%$ of the sample). ${ }^{15}$ The table demonstrates that baseline characteristics are again balanced. Compared to the full sample, baseline contributors are older, less likely to be male, and more likely to contribute in baseline year 2012 (65\%), with a much larger (unconditional) average contribution in $2012(€ 22.0)$.

Measure of intrinsic motivation. We use individual-level data on baseline contribution behavior (2005-2012) to measure intrinsic motivation. First, we distinguish between baseline non-contributors and baseline contributors to perform sample splits. Second, we use the relative frequency of contributing in the baseline as a continuous measure of intrinsic motivation within the group of baseline contributors. ${ }^{16}$ In section 5.2, we discuss robustness with respect to measuring intrinsic motivation by baseline payments rather than payment frequency. Table 2 presents sample sizes for treatment groups by motivational type (baseline contributors vs. baseline non-contributors).

\section{Results From the Field Experiment}

This section presents the evidence from the field experiment. We focus on the effects of the tax treatments relative to the donation treatment. To study the crowding out of intrinsic motivation, we consider the sample of baseline contributors. The compliance effects are identified from the sample of baseline non-contributors. In the Online Appendix, we compare the donation treatment to the control group and demonstrate that providing a reference point alone has the predicted effects: it increases the probability of contributing among baseline non-contributors and serves as an anchor when individuals decide about how much to give (see Online Appendix, Part B and Tables A3 and A4).

Throughout the paper, we report treatment effects from linear regressions controlling for strata variables and parish fixed effects. ${ }^{17}$ All tables display robust standard errors.

\footnotetext{
${ }^{15}$ We note that the level of intrinsic motivation revealed by baseline contribution behavior in our setting is in the same range as in DellaVigna et al. (2012), who study a charitable giving context and find that $25 \%$ of individuals are intrinsically motivated to give.

${ }^{16}$ Across eight pre-treatment years used to measure baseline motivation, the average individual is observed in 6.7 years. In our estimations, we restrict attention to baseline contributors observed in at least three pre-treatment years.

${ }^{17}$ Point estimates with and without controls are very similar (with slightly smaller standard errors when using controls). See Tables A3 and A4 in the Online Appendix for a comparison of estimates with and without controls.
} 


\subsection{Crowding Out of Intrinsic Motivation}

Table 3 documents responses of baseline contributors to the tax treatments relative to the donation treatment. We allow for heterogenous treatment effects in terms of baseline intrinsic motivation by including interaction terms between treatment indicators and baseline motivation. With $k=$ \{voluntary, compulsory\} denoting the treatments, the estimation equation thus reads

$$
y_{i}=c+\alpha m_{i}+\sum_{k} \beta^{k} T_{i}^{k}+\sum_{k} \gamma^{k} m_{i} \times T_{i}^{k}+x_{i} \delta+\epsilon_{i}
$$

where $y_{i}$ denotes the outcome studied, $m_{i}$ is individual $i$ 's motivation, $T_{i}^{k}$ denotes the indicator for treatment $k, x_{i}$ is a vector comprising the strata variables and parish fixed effects, and $\epsilon_{i}$ is an error term.

Columns (1) to (4) refer to treatment effects in the treatment year. Panel A displays our main findings on the crowd-out of intrinsic motivation by pooling the voluntary and the compulsory tax treatments. Specifically, the estimations in Panel A test whether imposing a tax norm as such affects contribution behavior. On the extensive margin, column (1) shows that communicating the existence of a legal norm significantly reduces the probability of contributing: if intrinsic motivation is very weak, the tax framing reduces the likelihood of contributing significantly. Evaluating the relative treatment effect for the pooled sample at the minimum of our measure for motivation of 0.125 (one year with strictly positive contribution out of eight baseline years), we estimate the tax letters to reduce the probability of contributing by 4.5 percentage points ( $p$-value: 0.049 ). Relative to the mean in the donation treatment, this corresponds to a reduction of the average probability of contributing by $7.3 \%$. This is a very conservative estimate of the relative size of the crowd-out, as the probability of contributing among the weakly intrinsically motivated is much lower compared to the average individual. Using as a reference point the local average probability of contributing among individuals who paid the levy in one out of eight baseline years, the relative crowd-out raises to $15.7 \%$. The crowding out effect disappears, however, if baseline intrinsic motivation is strong: then, the negative baseline effect is fully offset by the positive interaction term. Columns (2) and (3) of Panel A display the pooled treatment effect on the probability of contributing weakly less and strictly more than the reference point of $€ 15$. The estimates show that crowding out of intrinsic motivation significantly reduces the probability of contributing larger amounts (again among the weakly intrinsically motivated), while we do not see any effect on the probability of contributing small amounts. The latter observation is particularly interesting. It suggests that

individuals with large baseline contributions mainly respond at the extensive margin by ceasing to contribute, instead of reducing their contribution at the intensive margin. Column (4) presents 
results on the total effect, summarizing extensive and intensive margin responses. The estimates confirm that informing individuals about the legal norm significantly reduces contributions by the weakly intrinsically motivated, but not by the strongly intrinsically motivated.

Having shown pooled treatment effects, we now turn to the individual effects of the two tax letters (Table 3, Panel B). The estimates reveal that the pooled crowd-out effect is driven by the voluntary tax letter: the least intrinsically motivated among baseline contributors are significantly less likely to contribute (-5.6 percentage points ( $p$-value: 0.035$)$, column $(1))$ under the voluntary tax treatment. Comparing the least intrinsically motivated between the voluntary tax and the donation treatment, this amounts to a $19.3 \%$ reduction in the probability of contributing. Again, this effect is fully driven by a decline in the probability of contributing more than the reference point of $€ 15$ (-5.5 percentage points ( $p$-value: 0.013$)$, column (3)). In total, the least intrinsically motivated individuals reduce their contribution by $43.5 \%$ (column (4), $p$-value: 0.030 ) on average.

The findings for the voluntary tax letter contrast with the results for the compulsory tax letter (see lower part of Panel B). Across all margins, we find that the effect of the compulsory tax letter is insignificant. We conjecture that this is due to the crowd-out of intrinsic motivation being (partly) compensated by a more binding legal norm. In part 5.4, we discuss a simple model highlighting a potential mechanism behind this result. We note, however, that the effects of the two tax treatments evaluated at the sample mean are not statistically different from each other. We will return to this point when discussing the evidence from the post-treatment survey (part 5.3), where we find the difference between the two tax treatments to be significant.

\subsection{Persistency of Crowding Out}

Having established the presence of a short-term crowding-out effect, we now turn to its persistency. In the year after treatment, we sent out the donation letter (exact same layout and wording as in the treatment year) to all individuals in the donation and tax treatment groups. That is, we fully removed any reference to the legal norm from the letters, which may restore the initial level of intrinsic motivation. It is possible, though, that even a one-time intervention which points individuals to the fact that the church levy is a tax has a persistent negative impact on contribution behavior (if individuals remember the legal norm from the previous letter).

Studying the payment data from the year 2014, we indeed find evidence suggesting a persistent, but attenuated, crowd-out. When we repeat the estimations from Table 3, columns (1) to (4), for the year after treatment, we obtain the same pattern of coefficients as before, but with much smaller

point estimates. With similar standard errors as before, the point estimates become insignificant where they were significant for the treatment year (results not reported). Columns (5) and (6) in 
Table 3 display the results if we consider the probability of a reduced contribution relative to the baseline year 2012 for the year of treatment and the year after treatment, respectively. Column (6) demonstrates that even after removing the information on the legal norm, the weakly intrinsically motivated in the voluntary tax group are significantly more likely to pay less compared to the baseline year 2012 .

To summarize, the evidence discussed so far suggests a crowding out of intrinsic motivation if voluntary contributions are turned into compulsory tax payments. However, the crowd-out appears to affect only the weakly intrinsically motivated.

\subsection{Compliance Responses}

We next consider baseline non-contributors and study compliance responses to the tax treatments. As revealed by baseline contribution behavior, there is no potential for a crowd-out effect on contributions in this group. That given, a standard compliance response should dominate among baseline non-contributors. Hence, we expect that imposing a legal norm increases contributions in this group if the norm is sufficiently binding. There is no variation in baseline motivation among baseline non-contributors, and so the estimation equation boils down to

$$
y_{i}=c+\sum_{k} \beta^{k} T_{i}^{k}+x_{i} \delta+\epsilon_{i}
$$

We first consider the effect of the voluntary tax letter. As it communicates a legal norm that is not made effective, we expect a small compliance effect (if any) among baseline non-contributors. This is confirmed in Table 4, which reports the treatment effects of the voluntary tax and the compulsory tax letters, again both evaluated relative to the donation letter. The table shows that the voluntary tax letter has no impact on behavior among baseline non-contributors: individuals are neither more likely to contribute in the presence of a non-binding norm (column (1)) nor more likely to increase their average contribution (column (4)). Given the sample size, the insignificance of these effects is unlikely to be driven by lack of power.

Second, we take a closer look at the treatment effects of the compulsory tax letter. We expect that the compulsory tax letter-if perceived as legally binding-should increase contributions among baseline non-contributors. More specifically, we expect this effect to be confined to the probability of contributing weakly less than the amount owed $(€ 15)$. This is exactly what we find. As Table 4 demonstrates, the compulsory tax letter increases the probability of contributing among baseline non-contributors by 0.6 percentage points (column (1)). Given the low probability of contributing in the comparison group, this corresponds to a relative increase by $26 \%$. The increase in the 
probability of contributing is entirely driven by an increase in the probability of contributing weakly below the requested amount $(+0.6$ percentage points or $+26 \%$, column $(2))$. As regards the total response, the compulsory tax letter increases the average contribution of baseline noncontributors by about $3.8 \%$ (column (4)).

\section{Robustness and Discussion}

We next discuss the strength of our empirical findings. We report three main robustness checks. First, in section 5.1 we test the robustness of the crowd-out effect when allowing for a more flexible specification instead of a linear interaction. Second, in section 5.2 we employ an alternative measure of intrinsic motivation based on baseline contribution behavior. While using the baseline payment frequency seems straightforward, the average pre-treatment payment is an obvious alternative. Third, in section 5.3 we report evidence from a post-treatment survey that allows us to cross-validate the crowd-out effect identified from the field data. Importantly, the cross-validation exercise rests on measures of intrinsic motivation that are not linked to baseline payment behavior, thus providing an additional robustness test as regards the measurement of intrinsic motivation. Finally, we provide a theoretical discussion that helps disentangling how the mode of collection affects the profile of contributions. The model suggests a mechanism to identify among which types of contributors we expect crowding out to be strongest and thus helps to interpret our empirical findings.

\subsection{Estimating the Crowd-Out: Specification}

Our regression results of the crowd-out in Table 3 are restrictive in that we assumed the crowd out to be linear in intrinsic motivation. To dig deeper, Table 5 reports the results on the crowd-out for a specification that allows treatment effects to differ with the strength of intrinsic motivation. It employs a series of dummies for the frequency of baseline payments as well as interactions with treatment indicators. We use one dummy each for individuals contributing in up to 25 percent of baseline years, 26 to 50 percent, 51 to 75 percent, and in more than 75 percent of baseline years, respectively. Table 5 confirms our main findings: communicating the legal norm crowds out intrinsic motivation, and the loss in motivation is most pronounced among the weakly motivated.

Panel A of Table 5 considers the pooled effects of the tax letters relative to the donation letter. It demonstrates that the likelihood of contributing is reduced by about 4.2 percentage points among individuals with a baseline contribution frequency below 0.25 . The point estimate is similar (but insignificant) for those with a contribution frequency between 0.25 and 0.5 . In 
contrast, the more strongly intrinsically motivated do not seem to respond to the tax treatments (point estimates are statistically insignificant and close to zero).

Panel B of Table 5 shows the relative differences in the probability of contributing for the two tax treatments separately. For the voluntary tax treatment, we note a distinct reduction in the probability of contributing by 5.5 percentage points among the weakly intrinsically motivated. Moreover, Panel B establishes a monotonic relation between baseline motivation and the strength of the treatment effect of the voluntary tax letter. The treatment effects of the compulsory tax letter are insignificant, consistent with the notion of compliance effects offsetting the motivational crowd-out.

\subsection{Alternative Measurement of Intrinsic Motivation}

The results discussed so far rely on the frequency of baseline contributions being a good proxy for intrinsic motivation. An alternative view is that amounts contributed in the baseline reflect intrinsic motivation. To see if this affects our results, we re-estimate the crowd-out using the average baseline contribution as a proxy for motivation. To insure us against the average baseline payment picking up mainly the effect of income on contribution behavior (instead of motivation), we employ a proxy for individual (taxable) income as an additional regressor. ${ }^{18}$

Table 6 reports the results. As before, we find that communicating the legal norm crowds out intrinsic motivation. More importantly, the pattern of heterogeneity with respect to baseline motivation is exactly the same as before. Panel A shows the effect of the tax letters pooled. We find that the tax letters negatively affect both the probability of contributing (column (1)) and the contributed amount (column (4)). Again, the individuals with the weakest intrinsic motivation are most adversely affected in their contribution behavior. When studying the voluntary and the compulsory tax letters separately in Panel B, we find that the overall effect is again driven by the voluntary tax letter. In line with our previous findings, the effects of the compulsory tax letter are insignificant.

\footnotetext{
${ }^{18}$ The proxy is derived from individual data on taxable incomes for about 35,000 members of the Protestant church in the urban area that we consider (for details on this data, including sources, see Dwenger et al. 2016). Using the data on Protestants, we construct the income proxy for our population of Catholics by defining a set of bins (based on zip code areas, age groups, gender, and marital status) and by assigning the average taxable income of Protestants in a given bin to all (Catholic) individuals who belong to the same bin. Aggregate statistics from the personal income tax statistics show that Catholics and Protestants in the region studied are very similar. Table A1 in the Online Appendix shows that Catholics are, on average, not different from the overall population across a number of characteristics, including income. We also directly compared aggregate statistics for Catholics and Protestants (results not reported) and did not find any significant differences.
} 


\subsection{Cross-Validating the Crowd-Out With Survey Data}

In our empirical analysis we include all payments received within the first 20 weeks of the experiment (corresponding to $94 \%$ of all payments effected until December 31, 2013). Shortly after week 20, survey questionnaires were sent out to all individuals who received either the donation letter or one of the tax letters $(N=29,841)$. The mailings comprised a short cover letter, a one-page questionnaire (see the Online Appendix for both documents), and a return envelope for anonymous and postage-free return of the questionnaire. The questionnaire surveyed attitudes towards the church and the church levy, church attendance habits, and the willingness to donate and volunteer in other than church contexts. In each item, respondents could choose between five ordered response options (Likert scale).

We pre-coded the questionnaires prior to the mail-out. ${ }^{19}$ The code allows us to recover from incoming questionnaires the respondent's household type, age, the local parish, church levy contribution in baseline year 2012, and church levy payment in 2013. Using pre-coded information, Table A5 in the Online Appendix demonstrates that all observable characteristics of survey respondents are balanced across treatments, but that survey respondents differ in observable characteristics from the average survey recipient. Compared to all individuals in the experiment, survey respondents are, on average, about 10 years older and more likely to be married. The probability of contributing in the baseline year 2012 is more than four times larger among respondents, translating into higher unconditional average contributions. ${ }^{20}$ We conclude that the sample of survey respondents is selective, but there is no evidence of differences in the selectivity of survey respondents between treatment groups.

The pre-coded information allows us to check the validity of our field-experimental measure of intrinsic motivation by linking it to survey-based proxies capturing the respondent's relation to her parish, church attendance habits, and charitable giving and volunteering in other contexts. Figure 2 depicts the corresponding (polychoric) correlations ( $\rho$, with standard errors in parentheses). The panels on the left-hand side (Panels A, C, and E) report the average probability of contributing in baseline year 2012 for each response category, while the panels on the right-hand side (Panels B, D, and F) report the average amount contributed for each response category. Overall, we observe a strong positive correlation between the survey-based measures of intrinsic motivation and baseline contribution behavior.

We now turn to the direct cross-validation of the crowd-out effect identified in the field exper-

\footnotetext{
${ }^{19}$ The code allows us to recover individual characteristics from the incoming survey questionnaires while protecting the privacy of respondents.

${ }^{20}$ Conditional on contributing, average contributions in both samples are almost identical (results not shown).
} 
iment. It consists of re-estimating equation (1) from the full sample of survey respondents. ${ }^{21} \mathrm{We}$ recover post-treatment contribution behavior from the information pre-coded on questionnaires and derive the same dependent variables as in Table 3. Unlike before, we do not rely on baseline contribution behavior as a proxy for intrinsic motivation but use survey responses instead. The pre-coded information allows us to estimate the crowd-out effect while conditioning on the exact same set of control variables as in the field experiment.

Table 7 reports effects on the probability of contributing (columns (1) to (3)) and on contributions (column (4) to (6)). ${ }^{22}$ The measures of motivation take values from 1 to 5 (higher values indicating stronger motivation), corresponding to the five ordered response categories for each of the motivational survey questions. Although the sample is confined to survey respondents and data limitations prevent us from focusing on baseline contributors, the table confirms our earlier finding of a significant crowding out of intrinsic motivation: among weakly intrinsically motivated individuals, the voluntary tax treatment has a negative effect both at the extensive and the intensive margin. ${ }^{23}$ To give an example, survey respondents who never attend church (motivational measure 'Church Attendance' takes value one) are 7.7 percentage points less likely to contribute in the voluntary tax group relative to the donation letter group. At the intensive margin, the effect is even more pronounced (minus $€-5.3$ or 30.9 percent). Again we find the effect of the compulsory tax treatment to be insignificant. Importantly, we can now reject the hypothesis that the effects of the two tax treatments are identical for all estimations where the coefficients of the voluntary tax treatment and the interaction are significant $(p$-values $<0.01)$. This supports our interpretation that a counteracting compliance effects compensates the revenue loss caused by crowding out of intrinsic motivation. ${ }^{24}$

\subsection{Exploring a Mechanism}

In the following, we develop a simple warm-glow model of public goods contributions to a charity (Andreoni 1989, 1990). ${ }^{25}$ The model highlights the role of one particular institutional feature,

\footnotetext{
${ }^{21}$ We do not consider compliance effects here as it seems natural to interpret the decision to respond to the survey itself as evidence of some intrinsic motivation. Note also that we can recover information on contributions for only one baseline year. This prevents us from making the same sample splits underlying Tables 3 and 4 .

${ }^{22}$ We pre-coded information on contributions using several bins. This removes outliers from the survey-based data and allows us to estimate the effect on contributions without taking logs.

${ }^{23}$ The fact that we do not find significant effects in column (3) is in line with Figure 2, Panel E, showing that the correlation between the baseline probability of contributing in 2012 and motivation measured by the frequency of charitable giving and volunteering in other contexts is rather weak.

${ }^{24}$ Table 7 also suggests that strongly intrinsically motivated survey respondents tend to respond positively to the voluntary tax treatment. One possible interpretation is that in this specific group of church members, the voluntary tax treatment is interpreted as a signal of trust.

${ }^{25}$ All proofs are relegated to Online Appendix D.
} 
namely the mode by which individual contributions are collected. We let the charity choose whether to collect the contributions as compulsory payments (taxes) or as voluntary contributions (donations), which is exactly the choice the Catholic Church faces in our experimental setting. To allow for the crowding-out effects studied in the field experiment, individuals' intrinsic motivation to give to the charity may be affected by the mode of collection. The model disentangles how the mode of collection affects the profile of contributions. In particular, the model suggests a mechanism to identify in which contributors' groups do we expect to observe stronger crowding out from the mode of collection.

Consider an economy with a continuum of individuals of mass 1 . Each individual has an initial income of $I$ and decides to allocate this income between two goods: a private consumption good $c$ and a contribution to a charity $d$. We assume that the decision to contribute is driven only by warm-glow. The utility function of an individual is given by

$$
U=u(c)+\Theta v(d)
$$

where the functions $u($.$) and v($.$) are increasing and strictly concave, and v(0)=u(0)=0$. The type $\Theta$ denotes the intrinsic motivation of the individual for contributing to the charity. The individual's budget constraint is given by $c+d \leq I$.

The charity operates in an institutional environment where it can decide on the mode of collection of individual contributions: the charity can accept donations, but it is also entitled to claim a mandatory contribution from all individuals of value $\hat{d}$. We therefore consider two modes of collection: a donation and a taxation mode. Under the donation mode, the charity does not try to recover the mandatory contribution from all individuals and let individuals freely decide whether and how much they want to donate. Under the taxation mode, the charity imposes a compliance constraint. This constraint represents the minimal level of contribution and captures the legal norm implied by a taxation mode so that $0 \leq \tau \hat{d} \leq d$. The parameter $\tau \in[0, \bar{\tau}]$, with $\bar{\tau} \leq 1$, reflects the degree to which the legal norm is binding. In our field experiment, we induce variation in $\tau$ by treatments communicating the existence of a tax law requiring individuals to make certain minimum payments.

We now turn to the key ingredient of our model: the idea that the warm-glow utility from giving might depend on the collection mode. To mirror our empirical findings, we consider an economy with three groups of individuals. Each group is characterized by a level of intrinsic motivation that is either zero, intermediate, or high. When the charity uses a donation (resp. taxation) frame, the individual's intrinsic motivation is given by $\Theta_{D} \in\{0, \underline{\theta}, \bar{\theta}\}$ (resp. $\Theta_{T} \in\left\{0, \underline{\theta}^{\prime}, \bar{\theta}^{\prime}\right\}$ ). To capture the idea that individuals' intrinsic motivation might decrease when switching from a donation to 
a taxation mode, we assume

$$
0<\underline{\theta}^{\prime}<\underline{\theta}<\bar{\theta}^{\prime} \leq \bar{\theta}
$$

We first present the schedule of contributions when the charity uses a donation mode.

\section{Proposition 1: Contributions under donation mode}

In the donation mode, the contribution of individuals with intrinsic motivation $\Theta_{D}$ equal to 0 , $\underline{\theta}$, and $\bar{\theta}$ is given by $0, \underline{d}$, and $\bar{d}$, respectively, with $0<\underline{d}<\bar{d}$.

Proposition 1 shows that individuals with intrinsic motivation separate themselves from the non-motivated ones and donate some positive contributions even if there is no enforcement of the contributions to the charity.

We assume that $\underline{\theta}$ is sufficiently large so that $\bar{\tau} \hat{d} \leq \underline{d} .{ }^{26}$ We next turn to the schedule of contributions when the charity uses a taxation mode.

\section{Proposition 2: Contributions under taxation mode}

In the taxation mode, the contribution of individuals with intrinsic motivation $\Theta_{T}$ equal to 0 , $\underline{\theta}^{\prime}$, and $\bar{\theta}^{\prime}$ is given by $\tau \hat{d}, \max \left\{\underline{d}^{\prime}, \tau \hat{d}\right\}$, and $\bar{d}^{\prime}$, respectively, with $0<\max \left\{\underline{d}^{\prime}, \tau \hat{d}\right\}<\bar{d}^{\prime}$ for any $\tau$.

Proposition 2 shows that individuals with no intrinsic motivation give (weakly) positive contributions in the taxation mode. These individuals are affected by the mandatory nature of the contribution through the compliance constraint. In particular, our model predicts that individuals with no intrinsic motivation contribute the minimal possible level. This is in line with our empirical results in part 4.3. Individuals with high intrinsic motivation do not get affected by the compliance constraint since they contribute strictly more than the mandatory requirement anyway. Finally, we assume that the mandatory contribution with the most binding legal norm $\bar{\tau} \hat{d}$ is such that $0<\underline{d}^{\prime} \leq \bar{\tau} \hat{d}^{27}$

The following proposition establishes our results regarding the crowding out of intrinsic motivation.

\section{Proposition 3: Crowding out of intrinsic motivation}

(I.) Weak legal norm: When the legal norm is not very binding so that $\underline{d}^{\prime}=\max \left\{\underline{d}^{\prime}, \tau \hat{d}\right\}$, the crowding out of intrinsic motivation when switching from donation to taxation mode leads to the

\footnotetext{
${ }^{26}$ This assumption is fulfilled in the church levy context and implies that, in the donation mode, individuals with an intermediate level of intrinsic motivation would contribute more than their contribution under the most binding legal norm in the taxation mode.

${ }^{27}$ This assumption implies that, in the taxation mode, individuals with an intermediate level of intrinsic motivation may be affected by the compliance constraint, depending on the degree to which the legal norm imposed by the charity binds. This assumption holds in our empirical setting.
} 
following schedule of contributions: $\underline{d}^{\prime}<\underline{d}<\bar{d}^{\prime} \leq \bar{d}$.

(II.) Strong legal norm: When the legal norm is sufficiently binding so that $\tau \hat{d}=\max \left\{\underline{d}^{\prime}, \tau \hat{d}\right\}$, the crowding out of intrinsic motivation when switching from donation to taxation mode can be partially compensated by enforced compliance. The schedule of contributions then becomes: $\tau \hat{d} \leq$ $\underline{d}<\bar{d}^{\prime} \leq \bar{d}$.

Proposition 3 shows a mechanism that could explain our main empirical findings: the switch from donation to taxation mode triggers a crowding out of intrinsic motivation that may lead to a decrease in contributions made by individuals with types $\underline{\theta}^{\prime}$ and $\bar{\theta}^{\prime}$ relative to their initial donations $\underline{d}$ and $\bar{d}$. For individuals with intermediate intrinsic motivation, the crowding out of intrinsic motivation under taxation mode can be partially compensated by making the legal norm more binding, i.e. increasing $\tau$, which was identified in part 4.1. In contrast, contributions of highly motivated individuals do not respond to making the legal norm more binding.

\section{Conclusion}

This paper studies how taxes as externally defined legal norms on contribution behavior affect the willingness to contribute to public goods provision. We implement our field experiment in an urban area in Germany where the Catholic Church collects the local church levy. Pre-treatment, the levy is collected as a voluntary contribution, despite the fact that it is legally a tax. Starting from this baseline, we implement treatments that aim at two distinct effects: crowding out of intrinsic motivation among those who previously contributed, and compliance responses among those who did not contribute in the first place.

We compare the contribution behavior of different motivational types between treatments that frame the church levy as a tax and a control letter asking for a voluntary contribution. Several novel findings emerge. First, individuals with regular baseline contributions (the strongly intrinsically motivated) do not show any response to the information that the church levy is a tax. Second, individuals contributing only occasionally in the baseline (the weakly intrinsically motivated) reduce their payments significantly in response to a treatment framing the church levy as a tax. The evidence suggests that this effect is mostly driven by a strong negative response to the voluntary tax treatment, which is consistent with the notion that imposing externally defined norms crowds out intrinsic motivation, but that a sufficiently strong compliance incentive can compensate the revenue effects of the crowd-out. Third, baseline non-contributors are more compliant if the communicated norm is binding (compulsory tax) but do not respond if it is nonbinding (voluntary tax). Our main findings are robust to several sensitivity tests, including a 
cross-validation exercise based on an extensive post-treatment survey.

Two main conclusions can be drawn from our findings. First, imposing external rules on contribution behavior crowds out individuals' intrinsic motivation to voluntarily contribute to public goods provision. Raising taxes may thus entail a hidden cost. The finding of a significant crowding out of intrinsic motivation complements recent evidence suggesting that the positive effects of better enforcement overcompensate any associated loss in intrinsic motivation (Dwenger et al., 2016). We conclude that imposing a tax norm as such crowds out intrinsic motivation, but once a tax frame is in place, the adverse effects of increasing the level of enforcement on individuals' intrinsic motivation seem to be modest. The finding of detrimental effects of imposing norms on contribution behavior also relates our study to findings of a hidden costs of control in the context of principal-agent relations (Falk and Kosfeld, 2006).

Second, the distinct heterogeneity in treatment responses uncovered by our analysis suggests that baseline motivation is an important factor that determines how subjects respond to external incentives. Depending on baseline motivation, incentives might thus lead to higher or lower individual effort. The evidence in this paper comes from a very specific institution, which naturally limits the generalizability of our findings. In fact, we note that treatment effects of the kind of intervention we study appear to display a lot of heterogeneity, which makes drawing conclusions on other settings even more difficult. The latter point relates our study to Huffman and Bognanno (2014), who show that workers respond very heterogeneously to incentives and conclude that the distribution of individual characteristics like worker personalities and preferences determines the overall effect of external incentives. The strong heterogeneity in treatment responses could also help to explain why results from previous studies on the net impact of external incentives on prosocial activities were mixed (Gneezy and Rustichini, 2000a; Ashraf et al., 2014; Chetty et al., 2014). One lesson to be drawn for future research on the extrinsic-intrinsic crowd-out would thus be to include the measurement of individuals' baseline motivation in the design of experimental work whenever possible. The insight that baseline motivation may have an influence in shaping individuals' responses to incentives and norms might also lead to fruitful extensions in the literature discussing tax-driven distortions more generally. For instance, it would be interesting to know how individuals' baseline motivation interacts with the labor supply response identified in the literature on income taxation (Blundell and MaCurdy, 1999; Mirrlees et al., 2010). 


\section{References}

Andreoni, J. (1989). Giving with Impure Altruism: Applications to Charity and Ricardian Equivalence. Journal of Political Economy, 97, 1447-1458.

- (1990). Impure Altruism and Donations to Public Goods: A Theory of Warm-Glow Giving. Economic Journal, 100, 464-477.

- (1993). An Experimental Test of the Public-Goods Crowding-Out Hypothesis. American Economic Review, 83, 1317-1327.

-, Erard, B. and Feinstein, J. (1998). Tax Compliance. Journal of Economic Literature, $36(2), 818-860$.

Ariely, D., Bracha, A. and Meier, S. (2009). Doing Good or Doing Well? Image Motivation and Monetary Incentives in Behaving Prosocially. American Economic Review, 99, 544-555.

Ashraf, N., Bandiera, O. and Jack, K. (2014). No Margin, No Mission? A Field Experiment on Incentives for Public Service Delivery. Journal of Public Economics, 120, 1-17.

BÉnabou, R. and Tirole, J. (2003). Intrinsic and Extrinsic Motivation. Review of Economic Studies, 70, 489-520.

— and - (2006). Incentives and Prosocial Behavior. American Economic Review, 96, 1652-1678.

Blumenthal, M., Christian, C. W. and Slemrod, J. (2001). Do Normative Appeals Affect Tax Compliance? Evidence from a Controlled Experiment in Minnesota. National Tax Journal, 54, 125-138.

Blundell, R. and MaCurdy, T. (1999). Labor Supply: A Review of Alternative Approaches. In O. Ashenfelter and D. E. Card (eds.), Handbook of Labor Economics, vol. 3, Amsterdam: Elsevier, pp. 1559-1695.

Cagala, T., Glogowsky, U. and Rincke, J. (2015). Who to Target in Fundraising? A Field Experiment on Gift Exchange, mimeo.

Catholic Church (2014). The Catholic Church in Germany. Facts \& Figures 2013/14, Secretariat of the German Bishops' Conference, Bonn.

Chetty, R., Saez, E. and Sandor, L. (2014). What Policies Increase Prosocial Behavior? An Experiment with Referees at the Journal of Public Economics. Journal of Economic Perspectives, 28, 169-188. 
Cooper, G. (1979). A Voluntary Tax? New Perspectives on Sophisticated Estate Tax Avoidance. Washington, D.C.: The Brookings Institution.

Deci, E. L. (1971). Effects of Externally Mediated Rewards on Intrinsic Motivation. Journal of Personality and Social Psychology, 18, 105-115.

— (1975). Intrinsic Motivation. New York: Plenum Press.

Del Carpio, L. (2013). Are the Neighbors Cheating? Evidence from a Social Norm Experiment on Property Taxes in Peru, mimeo.

Della Vigna, S., List, J. A. and Malmendier, U. (2012). Testing for Altruism and Social Pressure in Charitable Giving. Quarterly Journal of Economics, 127, 1-56.

Dwenger, N., Kleven, H. J., Rasul, I. and Rincke, J. (2016). Extrinsic and Intrinsic Motivations for Tax Compliance: Evidence from a Field Experiment in Germany. American Economic Journal: Economic Policy, 8, 1-31.

Esteves-Sorensen, C., Macera, R. and Broce, R. (2013). Do Monetary Incentives Crowd Out Intrinsic Motivation? A Field Test in the Workplace, mimeo.

FALK, A. (2007). Gift Exchange in the Field. Econometrica, 75, 1501-1511.

- and Kosfeld, M. (2006). The Hidden Costs of Control. American Economic Review, 96, $1611-1630$.

Fellner, G., Sausgruber, R. and Traxler, C. (2013). Testing Enforcement Strategies in the Field: Threat, Moral Appeal and Social Information. Journal of the European Economic Association, 11 (3), 634-660.

Frey, B. S. and Oberholzer-Gee, F. (1997). The Cost of Price Incentives: An Empirical Analysis of Motivation Crowding-Out. American Economic Review, 87, 746-755.

Friedrichsen, J., Engelmann, D. (2014). Who Cares for Social Image?, mimeo.

- and - (2000a). Pay Enough or Don't Pay at All. Quarterly Journal of Economics, 115, $791-810$.

— and Rustichini, A. (2000b). A Fine Is a Price. Journal of Legal Studies, 29, 1-17. 
Hallsworth, M., List, J., Metcalfe, R. and Vlaev, I. (2014). The Behavioralist As Tax Collector: Using Natural Field Experiments to Enhance Tax Compliance, NBER Working Paper No. 20007.

Huck, S. and Rasul, I. (2011). Matched Fundraising: Evidence from a Natural Field Experiment. Journal of Public Economics, 95, 351-362.

Huffman, D. and Bognanno, M. (2014). Does Performance Pay Crowd Out Worker NonMonetary Motivations? Evidence from a Real Work Setting, mimeo.

Kleven, H. J., Knudsen, M. B., Kreiner, C. T., Pedersen, S. and Saez, E. (2011). Unwilling or Unable to Cheat? Evidence From a Tax Audit Experiment in Denmark. Econometrica, 79, 651-692.

Lacetera, N., Macis, M. and Slonim, R. (2012). Will There Be Blood? Incentives and Displacement Effects in Pro-Social Behavior. American Economic Journal: Economic Policy, 4, 186-223.

Landry, C. E., Lange, A., List, J. A., Price, M. K. and Rupp, N. G. (2010). Is a Donor in Hand Better than Two in the Bush? Evidence from a Natural Field Experiment. American Economic Review, 100, 958-983.

Luttmer, E. F. P. and Singhal, M. (2014). Tax Morale. Journal of Economic Perspectives, 28, 149-168.

Mellström, C. and Johannesson, M. (2008). Crowding out in Blood Donation: Was Titmuss Right? Journal of the European Economic Association, 4, 845-863.

Mirrlees, J., Adam, S., Besley, T., Blundell, R., Bond, S., Chote, R., Gammie, M., Johnson, P., Myles, G., and Poterba, J. (2010). Dimensions of Tax Design. The Mirrlees Review, Oxford University Press.

Pruckner, G. J. and Sausgruber, R. (2013). Honesty on the Streets: A Field Study On Newspaper Purchasing. Journal of the European Economic Association, 11, 661-679.

Rincke, J. and Traxler, C. (2011). Enforcement Spillovers. Review of Economics and Statistics, 93, 1224-1234.

Slemrod, J. (1998). On Voluntary Compliance, Voluntary Taxes, and Social Capital. National Tax Journal, 51, 485-491. 
-, Blumenthal, M. and Christian, C. (2001). Taxpayer Response to an Increased Probability of Audit: Evidence from a Controlled Experiment in Minnesota. Journal of Public Economics, 79, 455-483.

SLiwkA, D. (2007). Trust as a Signal of a Social Norm and the Hidden Costs of Incentive Schemes. American Economic Review, 97, 999-1012. 
Table 1: Individual Characteristics by Treatment Assignment

\begin{tabular}{|c|c|c|c|c|c|c|c|c|c|}
\hline $\begin{array}{l}\text { Number of } \\
\text { individuals }\end{array}$ & Age & $\begin{array}{l}\text { Male } \\
\text { Single } \\
\text { [yes=1] }\end{array}$ & $\begin{array}{c}\text { Male } \\
\text { Married } \\
\text { [yes=1] }\end{array}$ & $\begin{array}{l}\text { Female } \\
\text { Married } \\
\text { [yes=1] }\end{array}$ & $\begin{array}{c}\text { Contributed in } \\
2012 \\
\text { [yes }=1]\end{array}$ & $\begin{array}{l}\text { Contribution } \\
\text { in } 2012 \\
\text { (in Euro) }\end{array}$ & $\begin{array}{l}\text { Number of Years } \\
\text { Individual is } \\
\text { Observed Prior to } \\
\text { Treatment }\end{array}$ & $\begin{array}{l}\text { Share of Pre- } \\
\text { Treatment Years } \\
\text { with Contribution }\end{array}$ & $\begin{array}{c}p \text {-value of the } F \text { - } \\
\text { test on Joint } \\
\text { Significance } \\
\text { (Relative to } \\
\text { Control) [Relative } \\
\text { to Donation] } \\
(10)\end{array}$ \\
\hline 9947 & $\begin{array}{c}52.22 \\
{[51.82 ; 52.62]}\end{array}$ & $\begin{array}{c}0.253 \\
{[0.244 ; 0.261]}\end{array}$ & $\begin{array}{c}0.238 \\
{[0.230 ; 0.247]}\end{array}$ & $\begin{array}{c}0.142 \\
{[0.135 ; 0.149]}\end{array}$ & $\begin{array}{c}0.116 \\
{[0.110 ; 0.122]}\end{array}$ & $\begin{array}{c}3.96 \\
{[3.65 ; 4.27]}\end{array}$ & $\begin{array}{c}6.70 \\
{[6.65 ; 6.74]}\end{array}$ & $\begin{array}{c}0.105 \\
{[0.099 ; 0.110]}\end{array}$ & $\begin{array}{c}- \\
{[0.982]}\end{array}$ \\
\hline 9947 & $\begin{array}{c}52.03 \\
{[51.63 ; 52.43]}\end{array}$ & $\begin{array}{c}0.253 \\
{[0.244 ; 0.261]}\end{array}$ & $\begin{array}{c}0.238 \\
{[0.230 ; 0.247]}\end{array}$ & $\begin{array}{c}0.142 \\
{[0.135 ; 0.149]}\end{array}$ & $\begin{array}{c}0.113 \\
{[0.107 ; 0.119]}\end{array}$ & $\begin{array}{c}3.92 \\
{[3.60 ; 4.24]}\end{array}$ & $\begin{array}{c}6.66 \\
{[6.62 ; 6.71]}\end{array}$ & $\begin{array}{c}0.103 \\
{[0.098 ; 0.108]}\end{array}$ & $\begin{array}{c}0.982) \\
-\end{array}$ \\
\hline 9947 & $\begin{array}{c}52.18 \\
{[51.78 ; 52.58]}\end{array}$ & $\begin{array}{c}0.253 \\
{[0.244 ; 0.261]}\end{array}$ & $\begin{array}{c}0.238 \\
{[0.230 ; 0.247]}\end{array}$ & $\begin{array}{c}0.142 \\
{[0.135 ; 0.149]}\end{array}$ & $\begin{array}{c}0.114 \\
{[0.108 ; 0.120]}\end{array}$ & $\begin{array}{c}3.76 \\
{[3.45 ; 4.07]}\end{array}$ & $\begin{array}{c}6.68 \\
{[6.63 ; 6.73]}\end{array}$ & $\begin{array}{c}0.105 \\
{[0.100 ; 0.110]}\end{array}$ & $\begin{array}{l}(0.984) \\
{[0.980]}\end{array}$ \\
\hline 9947 & $\begin{array}{c}52.27 \\
{[51.88 ; 52.67]}\end{array}$ & $\begin{array}{c}0.253 \\
{[0.244 ; 0.261]}\end{array}$ & $\begin{array}{c}0.238 \\
{[0.230 ; 0.247]}\end{array}$ & $\begin{array}{c}0.142 \\
{[0.135 ; 0.149]}\end{array}$ & $\begin{array}{c}0.114 \\
{[0.108 ; 0.120]}\end{array}$ & $\begin{array}{c}3.86 \\
{[3.57 ; 4.16]}\end{array}$ & $\begin{array}{c}6.67 \\
{[6.62 ; 6.72]}\end{array}$ & $\begin{array}{c}0.105 \\
{[0.100 ; 0.110]}\end{array}$ & $\begin{array}{l}(0.945) \\
{[0.993]}\end{array}$ \\
\hline
\end{tabular}

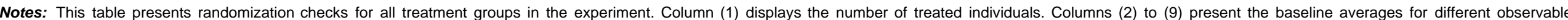

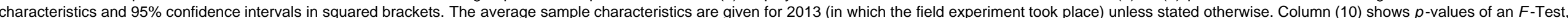
testing whether the observable characteristics are jointly significant in predicting assignment to treatment relative to the control group (round brackets) and relative to the donation treatment group (squared brackets). 
Table 2: Sample Sizes

Treatment Group

Number of Number of Baseline Number of Baseline

Individuals Contributors (Intrinsically Non-Contributors

Motivated)

(1)

(2)

(3)

\begin{tabular}{llll}
\hline Control Group & 9947 & 1708 & 8239 \\
Donation Letter Treatment & 9947 & 1692 & 8255 \\
Voluntary Tax Treatment & 9947 & 1693 & 8254 \\
Compulsory Tax Treatment & 9947 & 1711 & 8236 \\
\hline Total Number of Observations & 39788 & 6804 & 32984 \\
\hline
\end{tabular}

Notes: This table presents sample sizes in each treatment cell. Columns (2) and (3) split the number of treated individuals into baseline contributors and baseline non-contributors. Baseline contributors made a strictly positive contribution at least once in pretreatment years 2005-2012 and were observed in at least three pre-treatment years. Baseline non-contributors did not make any contribution in pre-treatment years 2005-2012. 
Table 3: Crowding Out of Intrinsic Motivation

Sample: Baseline Contributors (Intrinsically Motivated)

Treatment Responses in ...

Year of Treatment

Year After

Treatment

\begin{tabular}{|c|c|c|c|c|c|}
\hline \multirow{2}{*}{$\begin{array}{c}\text { Effect on } \\
\text { Probability of } \\
\text { Contributing }\end{array}$} & \multicolumn{2}{|c|}{$\begin{array}{c}\text { Effect on Probability of } \\
\text { Contribution ... }\end{array}$} & \multirow{2}{*}{$\begin{array}{c}\text { Effect on } \\
\text { Contribution (in } \\
\text { logs) }\end{array}$} & \multirow{2}{*}{$\begin{array}{c}\text { Effect on Prob. of } \\
\text { Reduced } \\
\text { Contribution } \\
\end{array}$} & \multirow{2}{*}{$\begin{array}{l}\text { Effect on Prob. of } \\
\text { Reduced } \\
\text { Contribution }\end{array}$} \\
\hline & $\leq$ Ref. Point & $>$ Ref. Point & & & \\
\hline (1) & (2) & (3) & (4) & (5) & (6) \\
\hline
\end{tabular}

Crowding Out Effects

(Tax Letters vs. Donation Letter)

A. Tax Letters, Pooled Effect

Tax Treatments

$\begin{array}{cccccc}-0.054^{\star \star} & -0.011 & -0.043^{\star} & -0.404^{\star \star} & 0.031 & 0.061^{\star \star} \\ (0.027) & (0.023) & (0.023) & (0.204) & (0.025) & (0.026) \\ 0.070^{\star \star} & 0.003 & 0.067^{\star} & 0.493^{\star} & -0.060 & -0.088^{\star *} \\ (0.035) & (0.036) & (0.038) & (0.271) & (0.038) & (0.041)\end{array}$

B. Tax Letters, Individual Effects

Voluntary Tax

Voluntary Tax x Baseline Probability of Contributing

$-0.068 *$

$(0.031)$

$0.099^{*}$

$(0.040)$

$-0.041$

$(0.031)$

0.042

Compulsory Tax $x$ Baseline Probability of Contributing

(0.041)

Average Outcome in Comparison Group

$62.5 \%$

Baseline Probability of Contributing

$59.5 \%$

5096

\begin{tabular}{cc}
-0.001 & $-0.067^{\star \star}$ \\
$(0.027)$ & $(0.026)$ \\
0.000 & $0.099^{\star \star}$ \\
$(0.042)$ & $(0.043)$ \\
-0.021 & -0.019 \\
$(0.026)$ & $(0.027)$ \\
0.005 & 0.037 \\
$(0.042)$ & $(0.044)$ \\
\hline $25.2 \%$ & $37.3 \%$ \\
$59.5 \%$ & $59.5 \%$ \\
5096 & 5096
\end{tabular}

$-0.523^{\star \star}$
$(0.234)$
$0.701^{\star \star}$
$(0.309)$
-0.289
$(0.238)$
0.292
$(0.316)$
$€ 20.55$
$59.5 \%$
5096

\begin{tabular}{cc}
$0.055^{\star}$ & $0.067^{\star \star}$ \\
$(0.029)$ & $(0.030)$ \\
$-0.099^{\star \star}$ & $-0.103^{\star \star}$ \\
$(0.045)$ & $(0.047)$ \\
0.008 & $0.054^{\star}$ \\
$(0.028)$ & $(0.030)$ \\
-0.022 & -0.074 \\
$(0.044)$ & $(0.047)$ \\
\hline $27.6 \%$ & $31.0 \%$ \\
$59.5 \%$ & $59.7 \%$ \\
5096 & 4777
\end{tabular}

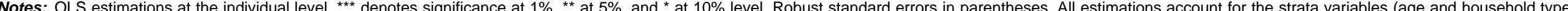

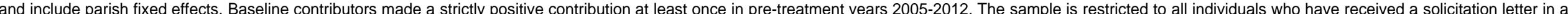

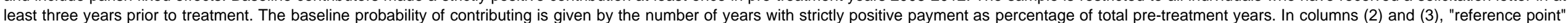
refers to the amount of $€ 15$. In columns (5) and (6), the outcome is the probability of a reduction in the contribution relative to the baseline year 2012. 
Table 4: Compliance Effects

\section{Sample: Baseline Non-Contributors}

\section{Effect on Probability of Contributing}

(1)
Effect on Probability of Contribution ... ... Below Ref. Point

(2)
... Above Ref. Point

(3)
Effect on Contribution (in logs)

(4)

\section{Compliance Effects}

(Tax Letters vs. Donation Letter)

\begin{tabular}{|c|c|c|c|c|}
\hline \multirow[t]{2}{*}{ Voluntary Tax } & -0.001 & -0.002 & 0.001 & -0.004 \\
\hline & $(0.002)$ & $(0.002)$ & $(0.001)$ & $(0.017)$ \\
\hline \multirow[t]{2}{*}{ Compulsory Tax } & $0.006^{\star *}$ & $0.006^{\star \star \star}$ & -0.000 & $0.038^{\star \star}$ \\
\hline & $(0.002)$ & $(0.002)$ & $(0.001)$ & $(0.018)$ \\
\hline Average Outcome in Comparison Group & $2.05 \%$ & $1.53 \%$ & $0.51 \%$ & $€ 0.37$ \\
\hline Number of Observations & 24745 & 24745 & 24745 & 24745 \\
\hline
\end{tabular}

Notes: OLS estimations at the individual level. ${ }^{* \star}$ denotes significance at $1 \%$, ${ }^{*}$ at $5 \%$, and ${ }^{*}$ at $10 \%$ level. Robust standard errors in parentheses. All estimations account for the strata

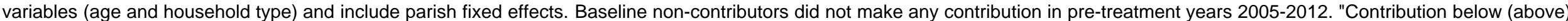
reference point" means contribution weakly below (strictly above) €15. 
Table 5: Alternative Specification to Test for Crowding Out of Intrinsic Motivation

Sample: Baseline Contributors (Intrinsically Motivated)

Effect on Probability of

Contributing
Effect on Probability of Contribution ...

$\leq$ Ref. Point

$>$ Ref. Point
Effect on Contribution (in logs)

\section{Crowding Out Effects}

(Tax Letters vs. Donation Letter)

\section{A. Tax Letters, Pooled Effect}

Tax Treatments x Baseline Probability $(0.00 ; 0.25]$

Tax Treatments x Baseline Probability $(0.25 ; 0.50]$

Tax Treatments x Baseline Probability $(0.50 ; 0.75]$

Tax Treatments x Baseline Probability $(0.75 ; 1.00]$ (1) (2)

(3)

(4)

\section{B. Tax Letters, Individual Effects}

Voluntary Tax x Baseline Probability $(0.00 ; 0.25]$

Voluntary Tax x Baseline Probability $(0.25 ; 0.50]$

Voluntary Tax x Baseline Probability $(0.50 ; 0.75]$

Voluntary Tax x Baseline Probability $(0.75 ; 1.00]$

Compulsory Tax x Baseline Probability $(0.00 ; 0.25]$

Compulsory Tax x Baseline Probability $(0.25 ; 0.50$

Compulsory Tax x Baseline Probability $(0.50 ; 0.75]$

Compulsory Tax x Baseline Probability $(0.75 ; 1.00]$

$\begin{array}{cc}-0.042^{\star} & -0.013 \\ (0.025) & (0.020) \\ -0.045 & 0.005 \\ (0.035) & (0.030) \\ 0.011 & -0.040 \\ (0.034) & (0.035) \\ 0.011 & -0.005 \\ (0.017) & (0.022)\end{array}$

-0.029
$(0.020)$
-0.049
$(0.032)$
0.051
$(0.036)$
0.015
$(0.024)$

$-0.354$

(0.273)

0.074
$(0.263)$

0.050

$(0.134)$

\begin{tabular}{|c|c|c|c|c|}
\hline Compulsory Tax x Baselıne Probability $(0.75 ; 1.00]$ & $\begin{array}{c}0.000 \\
(0.019)\end{array}$ & $\begin{array}{c}-0.014 \\
(0.025)\end{array}$ & $\begin{array}{c}0.014 \\
(0.028)\end{array}$ & $\begin{array}{c}0.000 \\
(0.156)\end{array}$ \\
\hline Average Outcome in Comparison Group & $62.5 \%$ & $25.2 \%$ & $37.3 \%$ & $€ 20.55$ \\
\hline Baseline Probability of Contributing & $59.5 \%$ & $59.5 \%$ & $59.5 \%$ & $59.5 \%$ \\
\hline Number of Observations & 5096 & 5096 & 5096 & 5096 \\
\hline
\end{tabular}

Notes: OLS estimations at the individual level. ${ }^{* \star *}$ denotes significance at $1 \%,{ }^{* \star}$ at $5 \%$, and $*$ at $10 \%$ level. Robust standard errors in parentheses. All estimations account for the strata variables (age and household type) and include parish fixed effects. Baseline contributors made a strictly positive contribution at least once in pre-treatment years 2005-2012. The sample is restricted to all individuals who have received a solicitation letter in at least three years prior to treatment. Baseline probability of contribution given by the number of years with strictly positive payment relative to total pre-treatment years. In 
Table 6: Crowding Out of Intrinsic Motivation With Baseline Amount Contributed as Measure of Intrinsic Motivation Sample: Baseline Contributors (Intrinsically Motivated)

\begin{tabular}{|c|c|c|c|}
\hline \multirow{2}{*}{$\begin{array}{c}\text { Effect on } \\
\text { Probability of } \\
\text { Contributing }\end{array}$} & \multicolumn{2}{|c|}{ Effect on Probability of Contribution } & \multirow{2}{*}{$\begin{array}{c}\text { Effect on } \\
\text { Contribution } \\
\text { (in logs) }\end{array}$} \\
\hline & $\leq$ Ref. Point & $>$ Ref. Point & \\
\hline (1) & (2) & (3) & (4) \\
\hline
\end{tabular}

\section{Crowding Out Effects}

(Tax Letters vs. Donation Letter)

\section{A. Tax Letters, Pooled Effect}

Tax Treatments

Tax Treatments $\times$ Baseline Amount Contributed

$\begin{array}{llll}-0.036^{\star} & -0.001 & -0.035 & -0.299^{\star} \\ (0.020) & (0.017) & (0.022) & (0.164) \\ 0.002^{\star \star} & -0.001 & 0.002^{\star} & 0.014^{\star} \\ (0.001) & (0.000) & (0.001) & (0.007)\end{array}$

\section{B. Tax Letters, Individual Effects}

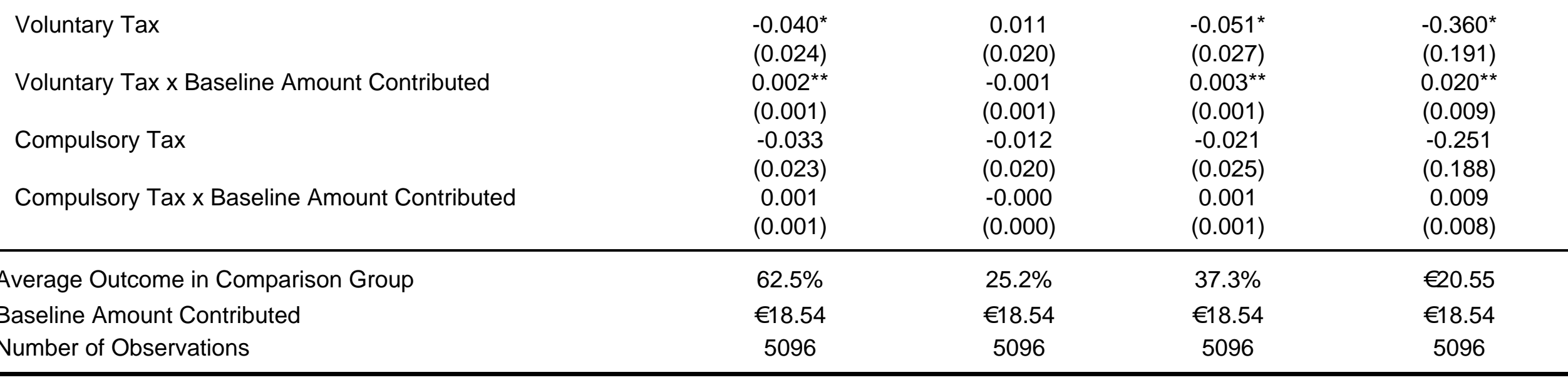

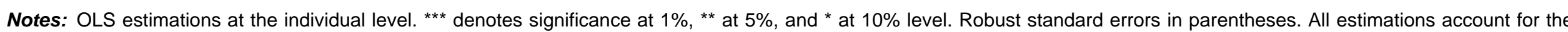

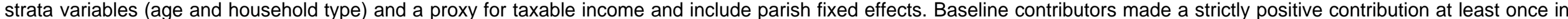

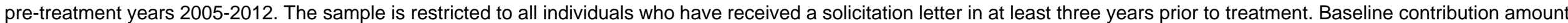
is given as the average contribution in pre-treatment years. In columns (2) and (3), "reference point" refers to the amount of $€ 15$. 
Table 7: Crowding Out of Intrinsic Motivation: Combining Payment Data with Survey-Based Measures of Motivation Sample: All Survey Respondents

\begin{tabular}{ccc} 
Effect on Probability of Contributing \\
\hline Motivation Measured by... \\
$\begin{array}{c}\text {...Relation to Local } \\
\text { Parish }\end{array}$ & $\begin{array}{c}\text {...Frequency of } \\
\text { Church Attendance }\end{array}$ & $\begin{array}{c}\text {...Charitable Giving } \\
\text { and Volunteering in } \\
\text { other Contexts }\end{array}$ \\
\hline
\end{tabular}

(1)

(2)

\begin{tabular}{ccc}
\multicolumn{3}{c}{ Effect on Contribution } \\
\hline $\begin{array}{c}\text { Motivation Measured by... } \\
\text { Parish } \\
\text { Pelation to Local } \\
\text { Pa...Frequency of } \\
\text { Church Attendance }\end{array}$ & $\begin{array}{c}\text { a.Charitable Giving } \\
\text { and Volunteering in } \\
\text { Other Contexts }\end{array}$ \\
\hline$(4)$ & $(5)$ & $(6)$
\end{tabular}
(6)

\section{Crowding Out Effects, Survey \\ (Tax Letters vs. Donation Letter)}

\begin{tabular}{|c|c|c|c|c|c|c|}
\hline Voluntary Tax & $\begin{array}{l}-0.105^{*} \\
(0.062)\end{array}$ & $\begin{array}{c}-0.134^{* *} \\
(0.062)\end{array}$ & $\begin{array}{l}-0.071 \\
(0.058)\end{array}$ & $\begin{array}{c}-6.64^{* *} \\
(3.05)\end{array}$ & $\begin{array}{c}-8.82^{* * *} \\
(2.86)\end{array}$ & $\begin{array}{c}-5.55^{\star *} \\
(2.56)\end{array}$ \\
\hline \multirow[t]{2}{*}{ Voluntary Tax x Motivation } & $0.036^{\star *}$ & $0.057^{* * *}$ & 0.025 & $2.13^{* *}$ & $3.52^{\star * *}$ & $1.71^{* *}$ \\
\hline & $(0.018)$ & $(0.022)$ & $(0.016)$ & $(0.929)$ & $(1.12)$ & $(0.810)$ \\
\hline \multirow[t]{2}{*}{ Compulsory Tax } & 0.076 & 0.045 & 0.009 & 0.617 & 0.269 & 0.886 \\
\hline & $(0.062)$ & $(0.062)$ & $(0.058)$ & $(2.96)$ & $(3.01)$ & $(2.56)$ \\
\hline \multirow[t]{2}{*}{ Compulsory Tax x Motivation } & -0.012 & -0.003 & 0.008 & 0.041 & 0.218 & -0.082 \\
\hline & $(0.018)$ & $(0.022)$ & $(0.016)$ & $(0.877)$ & $(1.11)$ & $(0.758)$ \\
\hline Average Outcome in Comparison Group & & $54.8 \%$ & & & $€ 17.16$ & \\
\hline Number of Observations & & 2321 & & & 2321 & \\
\hline
\end{tabular}

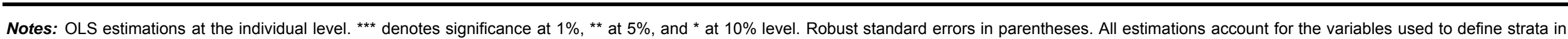

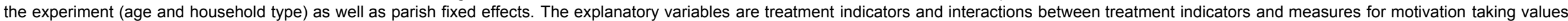

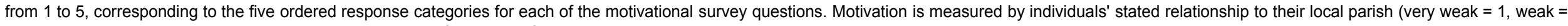

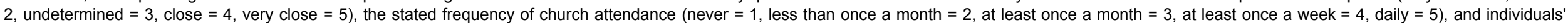

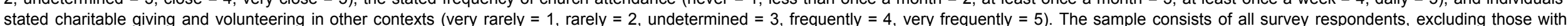

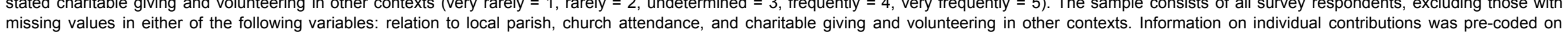
missing values in either of the follo
questionnaires prior to mail-out. 
Figure 1: Baseline Contributions in 2012, Conditional on Paying

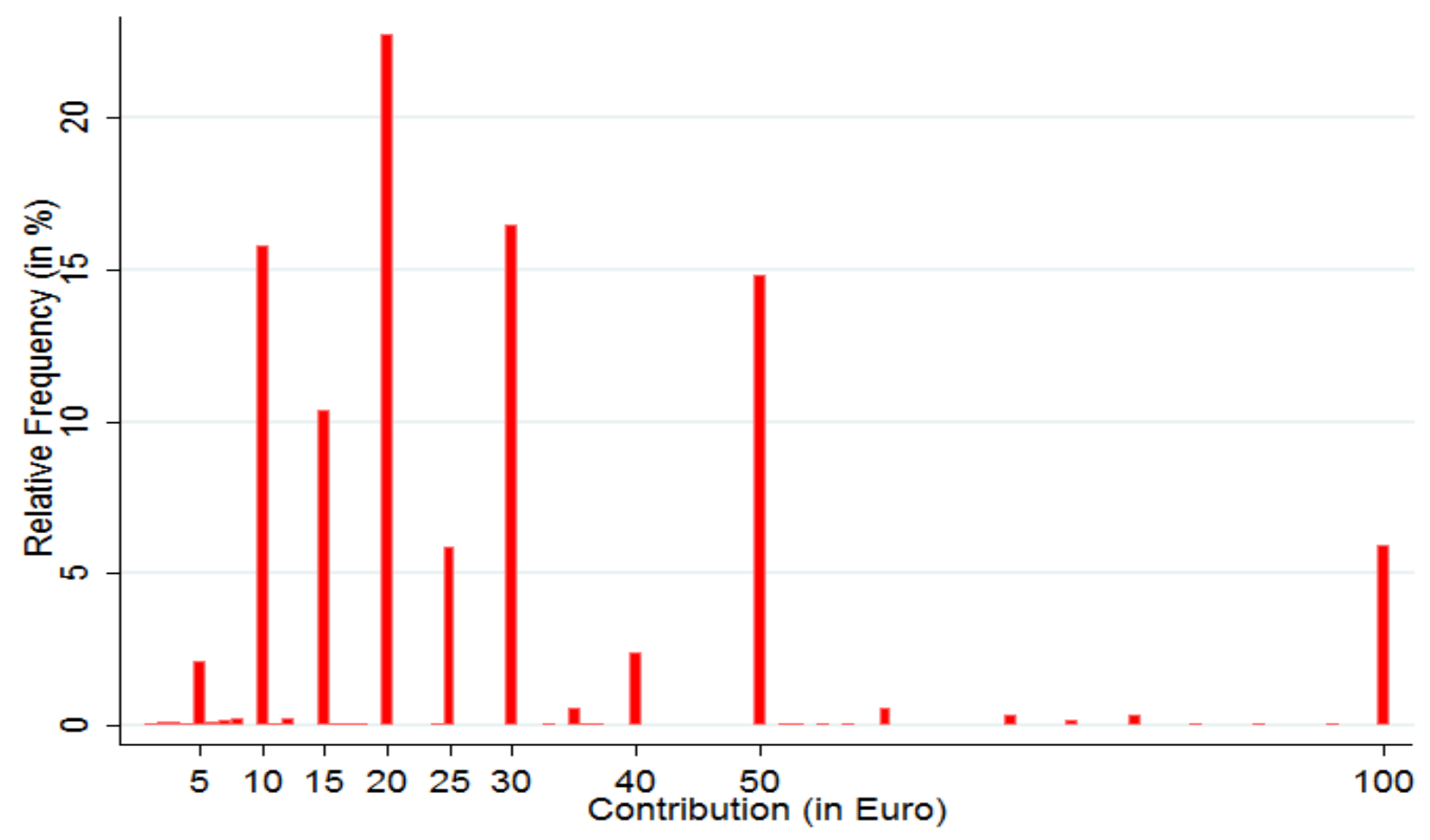

Notes: The figure displays the empirical density distribution of contributions made. More than $90 \%$ of contributions amounted to $10,15,20,25,30,50$ or 100 Euro (focal points). The sample consists of all baseline contributors (baseline year 2012). The bin size is one Euro. 
Figure 2: Baseline Contribution Behavior by Relation to Parish, Charitable Giving, and Church Attendance

A: Relation to Local Parish vs.

Probability of Contributing in 2012

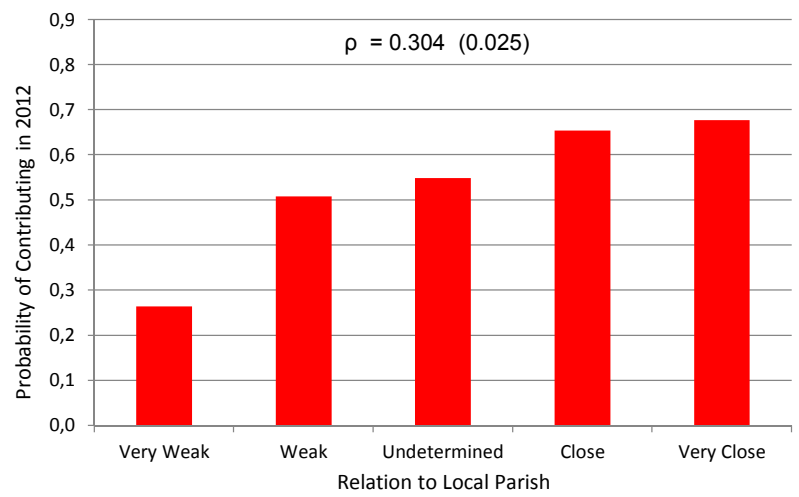

C: Church Attendance vs.

Probability of Contributing in 2012

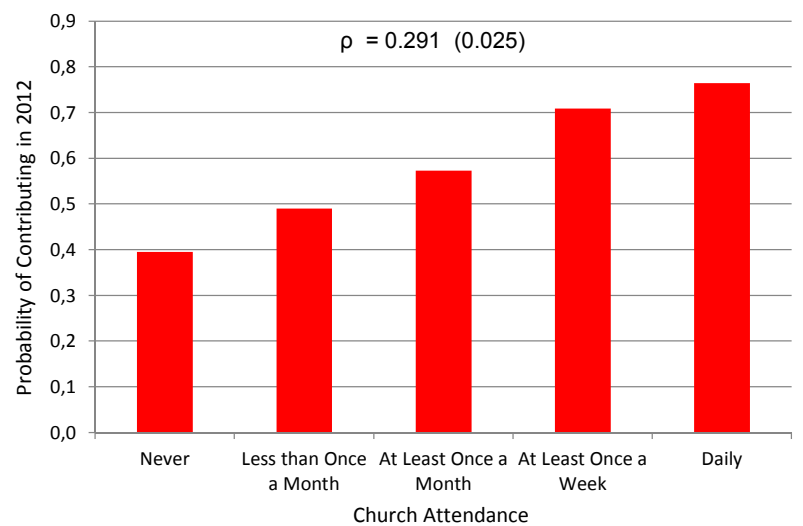

E: Charitable Giving and Volunteering in Other Contexts vs. Probability of Contributing in 2012

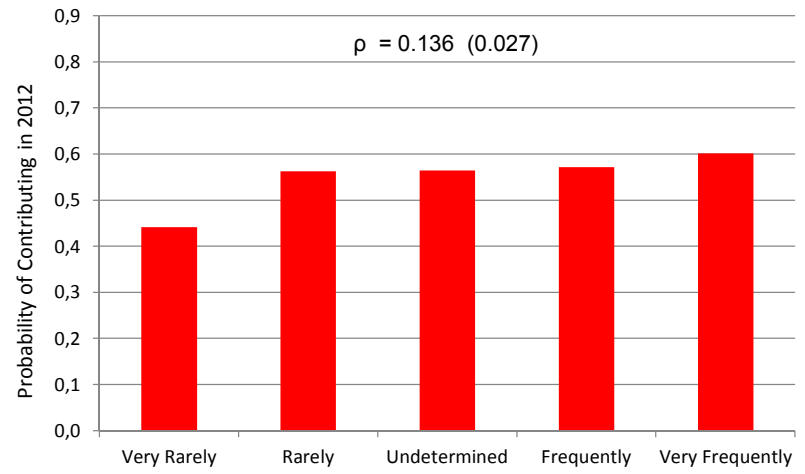

Charitable Giving and Volunteering in Other Contexts
B: Relation to Local Parish vs. Amount Contributed in 2012

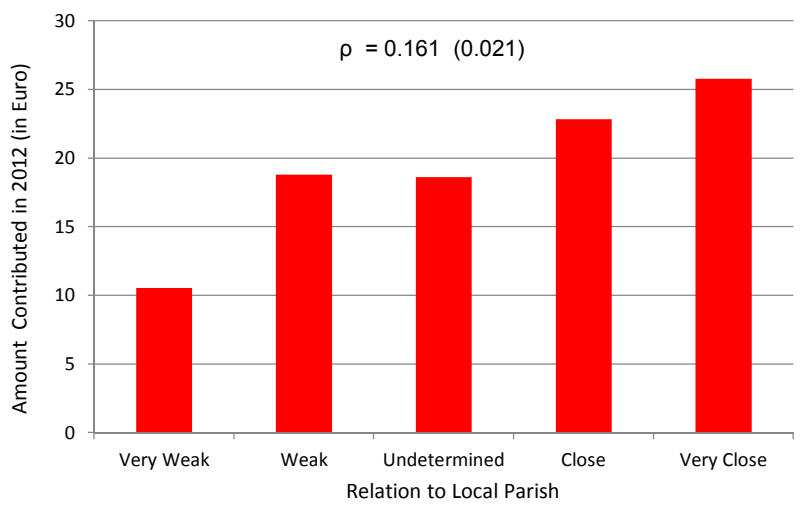

D: Church Attendance vs.

Amount Contributed in 2012

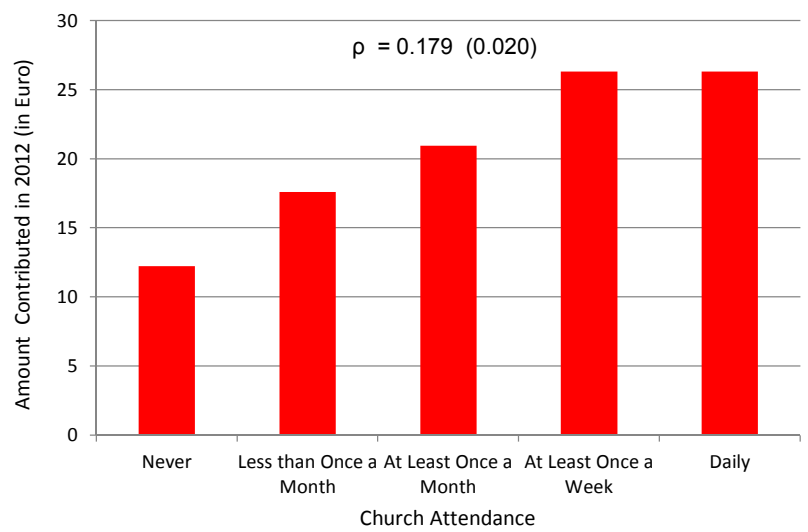

F: Charitable Giving and Volunteering in Other Contexts vs. Amount Contributed in 2012

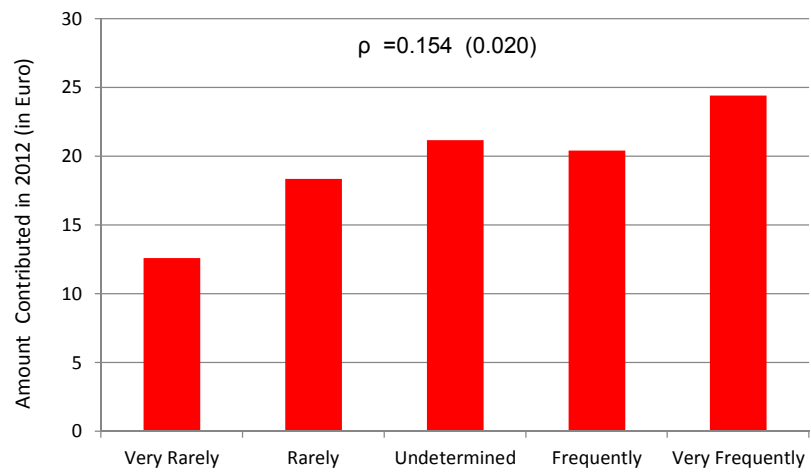

Charitable Giving and Volunteering in Other Contexts

Notes: This figure shows the correlations between baseline contribution behavior in 2012 and survey responses on respondents' relation to their local parish (Panels A and B), respondents' church attendance (Panels $C$ and $D$ ), and charitable giving and volunteering in other contexts (Panels $E$ and $F$ ). In each panel, we distinguish five ordered response categories (Likert scale) on the $x$-axis. Panels A, C, and E report the average probability of contributing for each response category, while Panels $B$, D, and F report the average amount contributed for each response category. The sample consists of all survey respondents, excluding those with missing values in either of the following variables: relation to local parish, contributed for each response category. The sample consists of all survey respondents, excluding those with missing values in either of the following variables: relation to local parish,
church attendance, charitable giving in other contexts, and amount contributed in $2012(\mathrm{~N}=2321)$. In each panel, we also report the polychoric correlation between the two motivational measures considered $(\rho)$, with standard errors in parentheses. The Information on individual contributions in 2012 was pre-coded on questionnaires prior to mail-out. 